\title{
Self-inflicted stab wound causing aorto-right ventricular fistula
}

\author{
P GODDARD, A G JONES, J D WISHEART \\ From The Department of Radiology and the Department of Cardiac Surgery, \\ Bristol Royal Infirmary, Bristol
}

SUMMARY A patient stabbed himself in the chest causing a penetrating cardiac injury which resulted in an aorto-right ventricular fistula. The presentation, diagnosis, and management were influenced by the patient's mental condition.

Stab injuries of the chest which not only penetrate the heart but also cause intracardiac damage are not commonly seen in Britain. This is the first reported case of self-inflicted aorto-right ventricular fistula.

\section{Case history}

A 39-year-old man was transferred to the Bristol Royal Infirmary in January 1978 in severe left ventricular failure one week after a self-inflicted stab wound to the left chest. He had a long and continuing history of psychiatric illness and had made several attempts on his life in the past. Previously, in 1973, he had stabbed himself in the chest in the fourth left intercostal space. This caused a half inch laceration in the anterior wall of the right ventricle which was closed with a buttressed suture at another hospital. While being treated for severe alcoholic depression he made a suicidal jump from a window in November 1977. During treatment in hospital for the resulting injuries he stabbed himself in the left chest anteriorly and was transferred to a nearby general hospital where the injury was considered to be superficial and the skin laceration was sutured. Severe pulmonary oedema developed, however, and a week later a continuous murmur at the left sternal border and a pericardial friction rub were heard. His heart rate was increased, the jugular venous pressure was raised, and the pulse pressure was widened (blood pressure $160 / 40 \mathrm{mmHg}$ ). There was right bundle-branch block on the electrocardiogram. The chest $x$-ray film showed cardiomegaly with bilateral pleural effusions and severe pulmonary oedema. It was evident that the injury had caused an intracardiac fistula and he was transferred to the Bristol Royal Infirmary for investigation and treatment.
After extensive consultation with his various medical advisers it was decided that immediate cardiac surgery was inappropriate because of his severe mental disturbance and, therefore, cardiac catheterisation was also deferred. He was treated conservatively and two weeks after admission both his mental and cardiac state had improved. Cardiac catheterisation was then performed and disclosed a left-to-right shunt apparently at ventricular level with an estimated pulmonary to systemic flow ratio of $2: 1$; pulmonary artery pressure was $27 / 13 \mathrm{mmHg}$ and the pulmonary wedge pressure was $16 \mathrm{mmHg}$. Aortography showed that there was a communication between the base of the right coronary sinus of Valsalva proximal to the right coronary ostium and the right ventricle. There was mild aortic regurgitation (Fig.). It was decided that surgical correction should be deferred until his mental state had improved further as his cardiac failure was relatively well controlled. Four months later his psychiatric condition had improved and his cardiac state had deteriorated, largely because of his failure to adhere strictly to the medical regimen. It was, therefore, decided to proceed with surgical treatment.

\section{OPERATION}

Operation was performed on 7 July 1978 when the heart was approached by a median sternotomy. There were widespread pericardial adhesions. Cardiopulmonary bypass was established before freeing the right ventricle from the pericardium. Dissection over the right ventricular outflow tract showed a false aneurysm corresponding to the entry site of the knife. The aortic end of the fistula was $1 \mathrm{~cm}$ long and was at the base of the right coronary sinus; there was a corresponding laceration in the right coronary cusp of the aortic valve, which would 


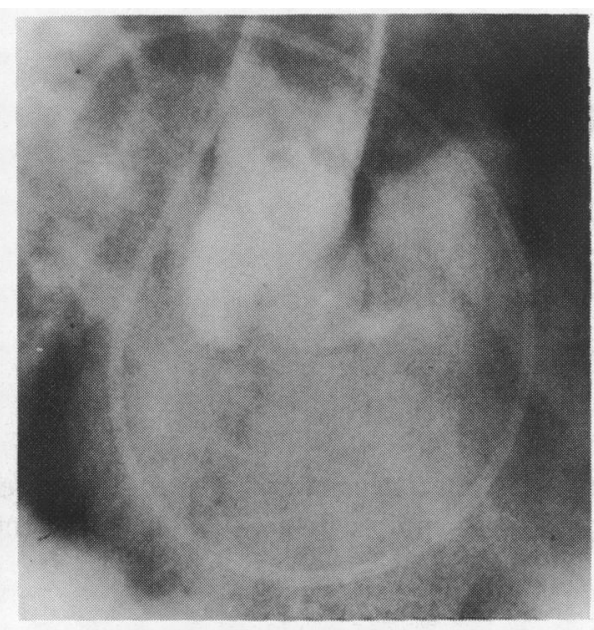

(a)

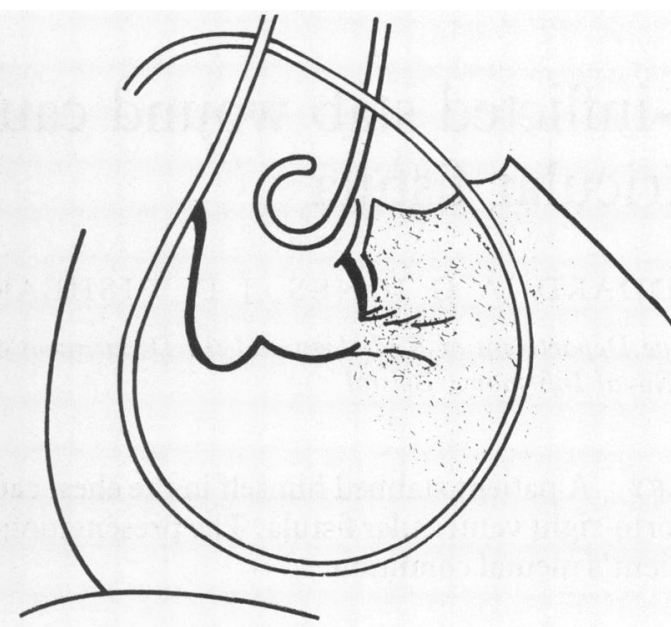

(b)

Fig. (a) Aortogram. (b) Line drawing. Contrast medium has been injected via a pigtail catheter into the aortic root in the steep right anterior oblique projection. A right heart catheter is in situ, through the pulmonary valve and in the wedge position. Contrast medium is shown jetting from the anterior sinus of Valsalva into the outflow tract of the right ventricle. The underside of the pulmonary valve is delineated.

account for the mild aortic regurgitation and which presumably indicated that the knife had been in situ during at least one systole. The right ventricular end of the fistula was inspected through a right ventriculotomy which was an extension of the neck of the false aneurysm; it was also $1 \mathrm{~cm}$ long and was situated a few $\mathrm{mm}$ superior to the papillary muscle of the conus.

The laceration of the right coronary cusp was repaired using a single continuous suture of $6(0)$ Prolene and the aortic end of the fistula was repaired with a continuous suture of 4(0) Prolene. The right ventricular end of the fistula was closed with two buttressed mattress sutures carefully placed in order to avoid the conducting tissue. The right ventricular outflow tract was repaired using buttressed sutures.

Postoperatively no murmurs or thrills were heard on auscultation and his general progress was excellent from a cardiac point of view.

Eight months later the patient was encouraged to lead a normal life and there was no evidence of any residual cardiac abnormality, though his mental state remained labile, with periods of intense depression.

\section{Discussion}

Wounds which penetrate the external wall of the heart are usually a result of injuries from a gun or a knife, and most of the reported cases are in American journals. This type of injury has been relatively un- common in Britain. ${ }^{1}$ The great majority of patients who suffer such injuries die before arrival at hospital ${ }^{2}$; the immediate mortality from gun shot wounds is two to three times greater than that of knife wounds. ${ }^{3}$ Immediately after resuscitative measures, which may include pericardiocentesis, surgical exploration and repair of the laceration of the heart wall should be carried out if there is a known or suspected penetrating injury. ${ }^{4}$ This approach has achieved survival in two-thirds of those patients who are admitted to hospital critically wounded with cardiac injuries.

Intracardiac sequelae of penetrating wounds of the heart include shunts, valvular lesions, retained foreign bodies, and complete heart block; myocardial infarction, ventricular aneurysm, congestive heart failure, and late onset haemopericarditis and tamponade may also occur. ${ }^{2} 3$ Of the reported fistulae, ventricular septal defects are most common, while aorto-right ventricular shunts are rare. There are 21 reported cases. All survived and all but three required operation. ${ }^{2}{ }^{5-17}$ Two were caused by gunshot wounds and the rest by knife wounds: the low number resulting from gunshot wounds probably reflects the fact that most patients with this type of injury to the heart die immediately.

An aorto-right ventricular shunt causes a continuous murmur and leads to heart failure because of the sudden increase in volume load on the left ventricle. Though the murmur may be present on admission, ${ }^{5} 10$ it may not develop for several days 
after the injury ${ }^{11} 1217$ and therefore a shunt may not be suspected until some days after the emergency operation to stop external bleeding from the heart. An accurate anatomical diagnosis should be obtained without delay by cardiac catheterisation and angiography. Early elective closure of the defect should be performed, as these patients are liable to rapid deterioration later.

Our patient's mental state influenced our management, as we considered it rendered him unfit for cardiopulmonary bypass at the time of admission to the Bristol Royal Infirmary. In so far as the initial treatment merely consisted of skin closure, this case also illustrates the danger of underestimating the seriousness of a penetrating chest wound.

The authors thank Dr D W Barritt under whose medical management the patient was admitted, and Dr I C Watt who not only carried out the investigations in this case but also offered helpful advice and criticism in the preparation of the manuscript.

\section{References}

1 McClintock FH, Avison NH, Rose GNG. Crime in England. London: Heinemann Press, 1968: 35-40.

2 Heller RF, Rahmitoola SH, Ehsani A, et al. Cardiac complications, results of penetrating chest wounds involving the heart. Arch Intern Med 1974; 134: 491-6.

3 Symbas PN, DiOrio DA, Tyras DH, Ware RE, Hatcher CR Jr. Penetrating cardiac wounds, significant residual and delayed sequelae. $\mathcal{F}$ Thorac Cardiovasc Surg 1973; 66: 526-32.

4 Mattox KL, Beall AC Jr, Jordan GL Jr, De Bakey ME. Cardiorrhaphy in the emergency centre. f Thorac Cardiovasc Surg 1974; 68: 886-95.

5 King H, Shumacker HB Jr. Surgical repair of traumatic aortic-right ventricular fistula. $\mathcal{f}$ Thorac Surg 1958; 35: 734-9.
6 Morris GC Jr, Foster RP, Dunn JR, Cooley DA. Traumatic aortico-ventricular fistula: report of two cases successfully repaired. Am Surg 1958; 24: 883-8.

7 Smyth NPD, Adkins PC, Kelser GA, Calatayud J. Traumatic aortic-right ventricular fistula. Surg Gynecol Obstet 1959; 109: 566-72.

8 Nowlan JA Jr, Steiger Z, Bicoff JP, Fell EA, Tobin JR Jr. Traumatic aortic-right ventricular fistula. f $A M A$ 1962; 181: 159-60.

9 Summerall CP III, Lee WH Jr, Boone JA. Intracardiac shunts after penetrating wounds of the heart. $N$ Engl f Med 1965; 272: 240-2.

10 Berger RL, Gibson H Jr, Riemer RW, Ramaswamy $\mathrm{K}$. Traumatic aortic regurgitation, ventricular septal defect and fistula of the sinus of Valsalva. $N \mathrm{Engl} \mathcal{F}$ Med 1969; 281 : 887-8.

11 Ehrenstein FL, Bahler RC, Ankeny J, Schwartz H. Untreated (combined) intracardiac and valvular trauma with long asymptomatic survival. Am Heart f 1971; 81: 685-7.

12 Norman JC, Weber WJ, Wilson WS, Sloan H. Post-traumatic fistula of the aorta, pulmonary artery and right ventricle. Ann Surg 1965; 161: 357-60.

13 Beall AC Jr, Hamit HF, Cooley DA, De Bakey ME. Surgical management of traumatic intracardiac lesions. F Trauma 1965; 5: 133-41.

14 Hutchinson JE, Schmidt DM, Cameron A, McCord $C W$. The surgical management of intracardiac defects due to penetrating trauma. $\mathcal{F}$ Thorac Cardiovasc Surg 1973; 65: 103-7.

15 Mulder DG. Stab wound of the heart. Ann Surg 1964; 160: 287-91.

16 Rogers MA, Chesler E, Du Plessis L. Surgical management of traumatic cardiac fistulae. Thorax 1969 ; 24 : 543-6.

17 Hardy JD, Timmis HH. Repair of intracardiac gunshot injuries, report of three cases. Ann Surg 1969; 169: 906-13.

Requests for reprints to J D Wisheart, Esq, FRCS, Department of Cardiac Surgery, Bristol Royal Infirmary, Bristol BS2 8HW. 